Journal of Biological Sciences, 2013

ISSN 1727-3048 / DOI: 10.3923/jbs.2013.

(C) 2013 Asian Network for Scientific Information

\title{
Molecular Mechanisms Involved in Murine Bone Marrow Erythropoietic Response to Acute Anaemia by Bleeding
}

\author{
Juan S. Todaro, Tania R. Stoyanoff, María V. Aguirre and Nora C. Brandan \\ Department of Biochemistry, Faculty of Medicine, National Northeast University, Corrientes, Argentina
}

\begin{abstract}
The underlying interactions among apoptosis, erythroid proliferation and differentiation involved in bone marrow erythropoietic response after an acute blood-loss have not yet been elucidated in detail. We hypothesized that Erythropoietin receptor, Bax, caspase-3, cytochrome c, Smac/DIABLO and Bcl- $\mathrm{x}_{\mathrm{L}}$ molecules play important roles at time of acute erythropoietic need to ameliorate the hypoxic stress. Experiments were performed using in vivo murine model of anaemia induced by blood-loss in a time course study of 15 days. Haematological parameters and bone marrow cellularities were determined. Bone marrow apoptotic assays included: double fluorescent staining (acridine orange/ethidium bromide) and TUNEL. Bone marrow clonogenic assays were performed for evaluating erythroid colony forming unit's expansion. The Erythropoietin receptor, Bax, Bcl- $\mathrm{x}_{\mathrm{L}}$ Smac/DIABLO, caspase-3 and cytochrome c expressions were assessed by immunoblottings. Caspase-3 activity was determined with a colorimetric assay kit. Bleeding induces bone marrow apoptosis from 1 to 3 days, concomitant with Bax over-expression and Bcl- $\mathrm{x}_{\mathrm{L}}$ decrease. The mitochondrial dysfunction caused cytochrome $\mathrm{c}$ and Smac/DIABLO release to cytosol and caspase-3 activation. Erythropoietic recovery was associated with Erythropoietin receptor over expression from the third day, concomitant with the erythroid progenitors and Bcl- $\mathrm{x}_{\mathrm{L}} / \mathrm{Bax}$ ratio enhancements. Erythropoiesis after bleeding depends on a delicate balance among proapoptotic (Bax, caspase-3, cytochrome c, Smac/DIABLO) and prosurvival proteins (Erythropoietin receptor, $\mathrm{Bcl}-\mathrm{x}_{\mathrm{L})}$, as the crucial regulators in bone marrow erythroid recovery. These findings provide new insights into the homeostatic mechanisms which promote erythropoietic response post-bleeding.
\end{abstract}

Key words: Apoptosis, bleeding, bone marrow, caspase-3-erythropoietin receptor

\section{INTRODUCTION}

The Erythropoietin (Epo) hormone is the main regulator of red cell production in mammals. In addition to its essential role in baseline erythropoiesis, Epo drives the erythropoietic stress response to low oxygen tension (Jelkmann, 2004). Epo circulating levels increase under anaemia, blood-loss or chemotherapy treatment to support the increment of the erythroid progenitors and the expansion of red cell compartment.

The Erythropoietin Receptor (Epo-R), which is expressed in bone marrow colony forming unit erythroid (CFU-E) progenitors and proerythroblasts (Broudy et al., 1991), plays a crucial role in promoting the physiological erythropoietic response. Binding of Epo to Epo-R results in proliferation and differentiation of erythroid cells (Jelkmann, 2004), through an up regulation of $\mathrm{Bcl}-\mathrm{x}_{\mathrm{L}}$, an antiapoptotic protein that is essential for erythroid survival (Silva et al., 1999; Gregoli and Boundurant, 1997).
In response to abnormal low Epo levels, erythroid progenitors exhibit an enhanced apoptosis (Testa, 2004), a well-controlled physiological mechanism for the maintenance of tissular homeostasis.

Two major pathways have been identified in the apoptotic regulation, the extrinsic and intrinsic pathways (Launay et al., 2005). The extrinsic pathway is mediated via surface death receptor leading to the activation of caspases-8 and 10 (Wallach et al., 2008). The intrinsic mitochondrial apoptotic pathway is regulated through Bcl-2 family proteins which maintain the mitochondrial outer membrane integrity (Cory and Adams 2002). Activated Bax forms pores in the mitochondrial membrane, inducing the release of proapoptotic molecules such as cytochrome $\mathrm{c}$ and Smac/DIABLO (second mitochondrial activator of caspases), which allows the activation of caspases-9, which in turn activate caspases-3, the most important executioner protease (Adrain and Martin, 2001; Deng et al., 2002; Parsons and Green, 2010).

Corresponding Author: María V. Aguirre, Department of Biochemistry, Biochemistry, Faculty of Medicine, National Northeast University, Moreno 1240 (3400), Corrientes, Argentina Tel/Fax: 54- 3783435378 


\section{J. Biol. Sci., 2013}

The induction of Bcl- $\mathrm{x}_{\mathrm{L}}$, has been proposed to be the primary mediator of the Epo antiapoptotic effect during differentiation (Gregory et al., 1999; Dolznig et al., 2002). Moreover, the severity of the anaemia has been related to the decrease of Bcl- $\mathrm{x}_{\mathrm{L}}$ expression, specifically in early erythroblasts (Socolovsky et al., 2001), as well as in late-stage erythroblasts (Rhodes et al., 2005).

The rate of red blood cell production can increase dramatically in an efficient and accelerated process known as stress erythropoiesis under certain conditions of tissue hypoxia (Erslev and Beutler, 1995). This physiologic process requires a considerable larger number of Epo-R than the necessary to maintain basal erythropoiesis (Socolovsky, 2007; Aispuru et al., 2008). It has been reported that, in healthy mice, the response under erythropoietic stress relies in bone marrow and spleen, depending on the acuity of erythrocyte mass reduction (Hara and Ogawa, 1977). Even though, the impact of the Epo-R and the role of apoptotic/survival related proteins in bone marrow cells during the bleeding recovery in an extended period of observation are still unclear.

Based on these outstandings, we hypothesized that Epo-R, caspase-3, cytochrome c, Smac/DIABLO, Bax and $\mathrm{Bcl}-\mathrm{x}_{\mathrm{L}}$ molecules play important roles at time of acute erythropoietic needs to ameliorate the hypoxic stress.

The aim of this study was to describe the changes in the erythroid bone marrow compartment related to the expression of Epo-R and apoptotic/survival molecules in response to anaemia in a murine experimental model of bleeding.

\section{MATERIALS AND METHODS}

Animals and experimental design: Female CF-1 Swiss mice (8-10 weeks old, 26-28 g) from the Animal Center of the Northeast National University, Argentina, were housed under temperature-and light-controlled environment, with food and water provided ad libitum.

The experimental procedures were approved by the Institutional Committee on the Ethic of Animal Experiments and were conducted following the Guide for the Care and Use of Laboratory Animals.

A total of 66 animals were used and randomly divided into two groups. In the first group $(n=42)$ anaemia was induced by micro capillary disruption of the retro-orbital plexus with drainage of $0.5 \mathrm{~mL}$ blood (one third of the calculated total blood volume) under ether anesthesia followed by repletion of blood volume with $0.5 \mathrm{~mL}$ of sterile saline solution $(0.9 \% \mathrm{NaCl}$ ) (Koury et al., 1989). To avoid iron deficiency, a single injection of iron dextran (10 $\mathrm{mg} \mathrm{kg}^{-1}$ of body weight i.p.; Sigma Chemical Co., St Louis, MO, USA) was administered. Experimental data from blood-loss treated group were compared to the control group $(\mathrm{n}=24)$ without treatment (day 0$)$. Animals were anesthetized with pentobarbital $\left(60 \mathrm{mg} \mathrm{kg}^{-1}\right.$ b.wt. i.p.) and bled by cardiac puncture at the each time of the experimental protocol $(1,2,3,5,7,10$ and 15 days $)$. Finally, they were euthanized by cervical dislocation.

Haematological and bone marrow parameters: Haematocrits and Haemoglobin $(\mathrm{Hb})$ concentrations were determined by standard methods. The reticulocyte count was performed manually on blood smears stained with Cresyl brilliant blue (1\%). The corrected reticulocyte count was calculated as described in the legend to Fig. 1.

Total bone marrow cells were determined as described previously (Aguirre et al., 2005). The total numbers of bone marrow nucleated cells were determined using a haemocytometer. Differential cell determinations were performed counting 1000 nucleated cells in
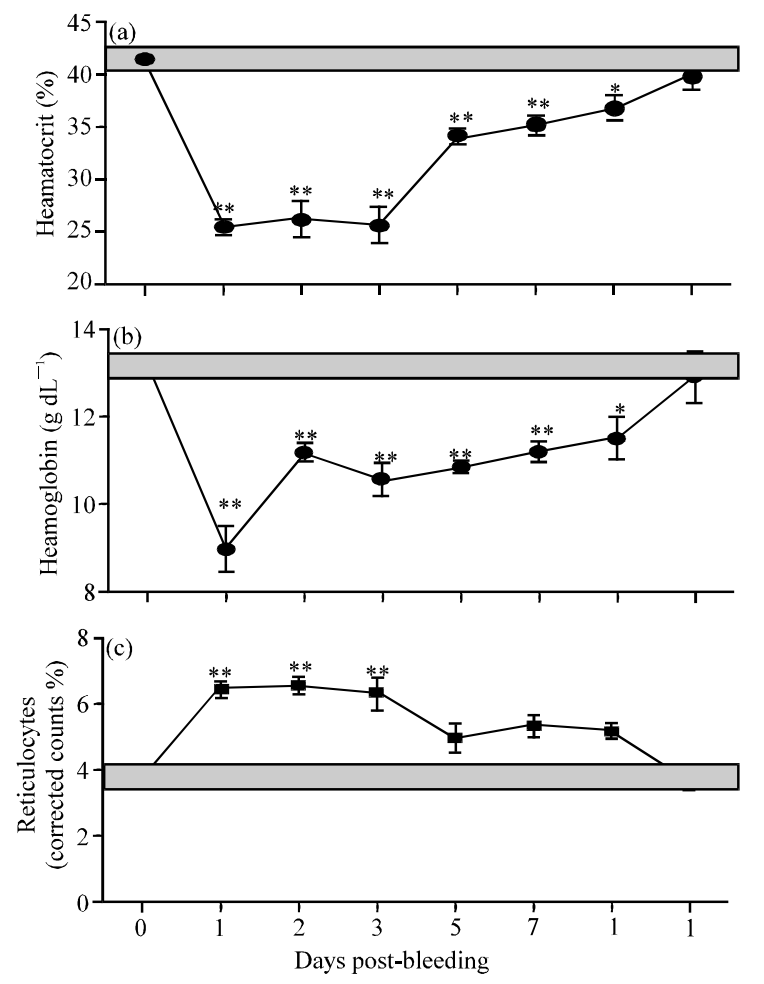

Fig. 1(a-c): Peripheral parameters during post-bleeding recovery (a) Haematocrits (\%) (b) Haemoglobin $\left(\mathrm{g} \mathrm{dL}^{-1}\right.$ ) and (c) Reticulocytes (corrected counts\%), Reticulocyte corrected index, assuming a baseline haematocrit of $42 \%$, equals reticulocyte count $(\%) \times$ (haematocrit/42). Data are presented as Mean \pm SEM, ${ }^{*} \mathrm{p}<0.05$ and ${ }^{* *} \mathrm{p}<0.01$, ANOVA and post hoc Dunnett test, between control group (day 0 ) and bled treated groups 
May-Gründwald-Giemsa stained smears and were classified into the following compartments: erythroid, myeloid and lymphoid cells. Results are expressed as absolute mean $\times 10^{6}$ cells/femur.

\section{Cell death assays}

Double Fluorescent staining: A simple double staining with Acridine Orange/ethidium Bromide $(\mathrm{AO} / \mathrm{EB})$ was utilized to determined cell death after bleeding procedure (Aguirre et al., 2010). Briefly, bone marrow cell suspension $\left(5 \times 10^{6}\right.$ cells $)$ were incubated with $20 \mu \mathrm{L}$ of $\mathrm{AO} / \mathrm{BE}$ dye mix just before microscopic observation at each time of the study. Slides were examined under fluorescence microscope (Olympus CX-35 equipped with Coolpix Digital camera) and the images were processed in Adobe Photoshop 8.0 (Adobe System, San Jose, Ca).

Late-apoptotic cells (bright orange chromatin with condensed or fragmented structure) were counted in several randomly selected independent fields (x 400). A total of 500 cells were counted to determine the percentage of apoptotic cell at each time of the protocol.

TUNEL assay: Apoptotic percentages of bone marrow cells were confirmed by TdT-mediate dUTP nick-end labelling (TUNEL) assay as reported previously (Romero Benitez et al., 2004). Briefly, samples fixed in 4\% paraformaldehyde were assayed using the Apopto Tag fluorescein direct in situ apoptosis kit (Intergen Co.,NY) according to manufacturer's instructions.

Apoptotic nuclei were stained positive for green fluorescence, while counterstaining showed red fluorescence with propidium iodide. The percentage of apoptotic cells was calculated from 5-10 randomly selected fields on each slide. A total of 500 cells were counted for every sample taken.

Clonogenic assays of haematopoietic progenitors: The number of colony-forming-units-erythroid (CFU-E) and burst-forming-unit-erythroid (BFU-E) from bone marrow cells was determined as described previously (Aguirre et al., 2005). Briefly, bone marrow cells $\left(2 \times 10^{5}\right.$ cells $\left.\mathrm{mL}^{-1}\right)$ were plated in triplicate on semisolid methylcellulose ( $1 \% \mathrm{w} / \mathrm{v}$, Fisher Co., USA) supplemented with $15 \%$ of fetal bovine serum and $3 \mathrm{IU} \mathrm{mL}^{-1}$ of recombinant human erythropoietin (rh-Epo; Hemax 2000, Biosidus, Argentina). Cultures were incubated at $37^{\circ} \mathrm{C}$ in a humidified air containing $5 \% \mathrm{CO}_{2}$. CFU-E were counted on the second day, meanwhile BFU-E were counted on day 7. Results are expressed as mean colonies/femur.

Western blot analysis: Epo receptor were performed by Western blot analysis from whole bone marrow extracts obtained in RIPA buffer $(50 \mathrm{mM}$ Tris, $150 \mathrm{mM} \mathrm{NaCl}$, $2.5 \mathrm{mg} \mathrm{mL}^{-1}$ deoxycholic acid, $1 \mathrm{mMEGTA}, 10 \mu \mathrm{g} \mathrm{mL}^{-1}$ Nonidet-40 ( $\mathrm{pH} 7.4)$, supplemented with protease inhibitors: $2.5 \mu \mathrm{g} \mathrm{mL} \mathrm{m}^{-1}$ leupeptin, $0.95 \mu \mathrm{g} \mathrm{mL} \mathrm{m}^{-1}$ aprotinin and $2.5 \mathrm{mM}$ Phenylmethylsulfonyl Fluoride [PMSF]) (Aguirre et al., 2005).

Immunoblottings for cleaved caspase- $3, \mathrm{Bcl}-\mathrm{x}_{\mathrm{L},}, \mathrm{Bax}$, cytochrome $\mathrm{c}$ and Smac/DIABLO were performed from cytosolic bone marrow lysates, according to the procedures reported previously (Aispuru et al., 2008). Briefly, single cell suspensions were lysed into ice-cold buffer (10 mM HEPES pH 7.4, $10 \mathrm{mM} \mathrm{KCl}, 1.5 \mathrm{mM} \mathrm{MgCl}_{2}$, $0.5 \mathrm{mM}$ dithiothreitol, 0.1\% IGEPAL (Sigma Co, MO, USA), supplemented with protease and phosphate inhibitor cocktail. Cell lysates were centrifuged at $14.000 \mathrm{~g}$ and the supernatant was used as cytosolic fraction.

The blotted membranes (Bio-Rad) were probed with 1:500 dilutions of primary anti-Bax, anti-Epo receptor, anti-Bcl- $\mathrm{L}_{\mathrm{L}}$ anti-Smac/DIABLO (Santa Cruz Biotechnology, Santa Cruz, CA, USA), anti-cleaved caspase-3 (Cell Signaling Technology) and anti-cytochrome c (BD-Pharmigen) or anti- $\beta$ actin (Sigma) followed by incubation with horseradish peroxidase-conjugated secondary antibodies (Jackson Immunoresearch Inc, USA). $\beta$ actin detection was used to normalize inmunoblottings.

Immunocomplexes were detected by an Opti4CN kit (Bio-Rad, CA, USA). Band optical density (OD) was analyzed using NIH-image software and results are expressed as the ratio: (protein of interest $O D / \beta$-actin $O D$ ) $\mathrm{x} 100$.

Caspase. 3 activity assay: Caspase- 3 activity was determined by a commercial colorimetric assay kit (Sigma, St Louis, USA) as reported previously (Aispuru et al., 2008). Proteolytic reactions were carried out in extraction buffer containing $20 \mu \mathrm{g}$ of cytosolic protein extract and $40 \mu \mathrm{M}$ of substrate (Ac-DEVD-pNA for caspase-3). Samples were incubated for an additional $2 \mathrm{~h}$ at $37^{\circ} \mathrm{C}$ and the release of pNA was measured at 405 $\mathrm{nm}$ using a colorimeter. Caspase- 3 activity was expressed as fold increase of untreated control.

Statistical analysis: Data was expressed as Mean \pm SEM. All data involving multiple groups were analyzed by one-way Analysis of Variance (ANOVA). Differences between individual groups were analyzed by one-way ANOVA followed by Dunnett test (Graph Pad Software Inc, San Diego, CA, USA). A p-value $<0.05$ was considered statistically significant. The correlations between different variables were performed using the Spearman rank correlation test.

\section{RESULTS}

Haematological parameters: Haematocrits, haemoglobin levels and reticulocyte counts were monitored during a 
Table 1: Bone marrow cellularities after bleeding

\begin{tabular}{|c|c|c|c|c|c|c|c|c|}
\hline \multirow[b]{3}{*}{ Day of sampling } & \multicolumn{8}{|l|}{ Cell type } \\
\hline & \multicolumn{2}{|c|}{ Total bone marrow cells ( $10^{6} /$ femur) } & \multicolumn{2}{|c|}{ Ery throid cells (x 106/femur) } & \multicolumn{2}{|c|}{ Myeloid cells (x $10^{6} /$ femur) } & \multicolumn{2}{|c|}{ Lymphoid cells (x 10/femur) } \\
\hline & Control & $\mathrm{HS}$ & Control & $\mathrm{HS}$ & Control & HS & Control & $\mathrm{HS}$ \\
\hline 1 & $16.8(0.5)$ & $9.9(0.6)^{* * *}$ & $3.7(0.4)$ & $2.1(0.4)^{* * *}$ & $9.0(0.7)$ & $4.9(0.6)^{\text {**** }}$ & $4.1(0.5)$ & $2.9(0.3)^{*}$ \\
\hline 2 & $15.5(0.8)$ & $4.0(0.4)^{* * * *}$ & $3.2(0.2)$ & $0.5(0.1)^{* * *}$ & $8.8(0.6)$ & $2.6(0.3)^{* * * *}$ & $3.5(0.2)$ & $0.9(0.2)^{\text {t****4}}$ \\
\hline 3 & $14.7(0.4)$ & $7.9(0.7)^{* * *}$ & $2.7(0.6)$ & $2.1(0.3)^{\text {***k }}$ & $8.0(0.5)$ & $3.6(0.4)^{\text {k*k }}$ & $4.0(0.6)$ & $1.6(0.5)^{\text {**** }}$ \\
\hline 5 & $16.0(0.7)$ & $10.7(0.5)^{* * *}$ & $3.0(0.3)$ & $2.4(0.5)^{* * *}$ & $9.1(0.3)$ & $5.1(0.5)^{* * *}$ & $3.9(0.4)$ & $3.2(0.5)$ \\
\hline 7 & $14.8(1.1)$ & $16.7(0.6)$ & $2.9(0.5)$ & $2.7(0.6)^{*}$ & $8.5(0.4)$ & $9.7(0.7)$ & $3.5(0.7)$ & $4.3(0.8)$ \\
\hline 10 & $15.8(0.9)$ & $15.5(0.8)$ & $3.2(0.4)$ & $2.2(0.2)^{\text {**** }}$ & $8.4(0.2)$ & $9.2(0.8)$ & $4.2(0.8)$ & $3.4(0.5)$ \\
\hline 15 & $16.3(0.8)$ & $16.0(0.5)$ & $3.4(0.7)$ & $2.4(0.5)^{* * * *}$ & $9.0(0.1)$ & $9.9(0.7)$ & $3.9(0.3)$ & $3.7(0.6)$ \\
\hline
\end{tabular}

Absolute cell No. from hematopoietic lineages in bone marrow were calculated from total femoral counts and different percentages at the scheduled times, Differential cell determinations were performed counting 500-1000 cells in May Grundwald-Giemsa (MGG) stained bone marrow smears. Haematological results were expressed as Mean $\times 10^{6}$ cells/femur \pm SEM. ( $n=6$ for controls group and HS groups) at each time points of the study from three independent experiments, $* * \mathrm{p}<0.01$ and $* \mathrm{p}<0.05$ indicates significant differences between the control group and HS group

time course study of 15 days post blood-loss (Fig. 1). Haematocrits decreased significantly from day 1 to day 3 compared to control $(25.2 \pm 0.40 \%$ vs. $42 \pm 0.86 \%$, p < 0.01$)$ (Fig. 1a). Haemoglobin concentration decreased to a minimal value of $9.0 \pm 0.52 \mathrm{~g} \mathrm{dL}^{-1}(\mathrm{p}<0.01)$ on day 1 , representing a reduction of $33 \%$ from the baseline of $13.15 \mathrm{~g} \mathrm{dL}^{-1}$ (Fig. $1 \mathrm{~b}$ ). Both parameters returned gradually to normal values at the end of the observation period.

The proportion of reticulocytes in the peripheral blood is indicative of the erythropoietic rate. The corrected reticulocyte count, also called reticulocyte production index, is the ratio between the level of anemia and the extent to which the reticulocyte count has risen in response. Corrected reticulocyte counts enhanced 3 fold over control from day 1 to day 3 post bleeding $(10.5 \pm 0.75$ vs. $2.90 \pm 0.15 \%, \mathrm{p}<0.01)$ and decreased progressively from day 5 , reaching baseline levels at the end of the experience (Fig. 1c).

This finding is characteristic of acute anemia and indicates loss of red blood cells leading to increased compensatory production of reticulocytes to replace the lost of mature circulating erythrocytes.

Table 1 shows total bone marrow cellularities decreased drastically to minimal values from 1 to 5 days (five times below control, $\mathrm{p}<0.01$ ) and returned to the normality from day 7 onward. Although, all bone marrow lineages exhibit a marked depletion, the red cell compartment was the most affected after bleeding procedure. Erythroid absolute bone marrow cellularities decreased 8.8 fold on the second day $(p<0.01)$; whilst the lymphoid and myeloid cells exhibited a 4-3.7-fold reduction, respectively, compared to control group $(\mathrm{p}<0.01)$.

Changes in differential cell count of erythroid precursor's subsets revealed that anaemia induced by bleeding affected the kinetic of bone marrow erythroid cells. On the third day, the proerythroblasts were the only erythroid precursors that reached normal values $(p<0.01)$. This pattern is characteristic of committed erythroblasts, which rapidly proliferate to achieve late stages of differentiation (Fig. 2). Nevertheless, the orthochromatic blasts reached control values on the fifth day. The apparent lack of increment of the basophilic and the polychromatophilic erythroblasts, seem to be due to the accelerated input of cells from the immature to the mature erythroid compartments.

Bone marrow death pattern: Apoptosis was assessed using $\mathrm{AO} / \mathrm{EB}$ staining (Fig. 3a) and by TUNEL assay (Fig. 3b). Percentage of apoptotic cells were obtained by TUNEL, a widely used confirmatory assay for cell death (Fig. 3c). Apoptotic indexes increased dramatically on the first day after bleeding $(25.7 \pm 2.3 \%$ vs. $6.5 \pm 0.3 \%, \mathrm{p}<0.01)$. Apoptosis remained increased between days 2 and 3 (3.2 and 2.9-fold over control respectively, $p<0.01$ ). The apoptotic index returned almost to the normality from day 5 onwards.

Altogether, these results indicate that bone marrow cells exhibit maximal apoptosis in coincidence with minimal cellularities between days 1 and 3 post-bleeding. A direct correlation between bone marrow cellularities and apoptosis indexes was extremely significant $(\mathrm{r}=0.91$; $\mathrm{p}=0.001)$.

Hematopoietic progenitor assays: Clonogenic assays were performed to assess the frequency of bone marrow erythroid progenitors: BFU-E and CFU-E throughout the study. Figure 4 shows BFU-E colony counts decreased to minimal values on the second day ( 0.5 fold under controls, $\mathrm{p}<0.01$ ), while el number of CFU-E remained without changes. The number of BFU-E and CFU-E progenitors increased from day 3 ( 2 fold above control, $\mathrm{p}<0.01)$ until the end of the experience. The enhancement of both erythroid progenitor populations (CFU-E and 

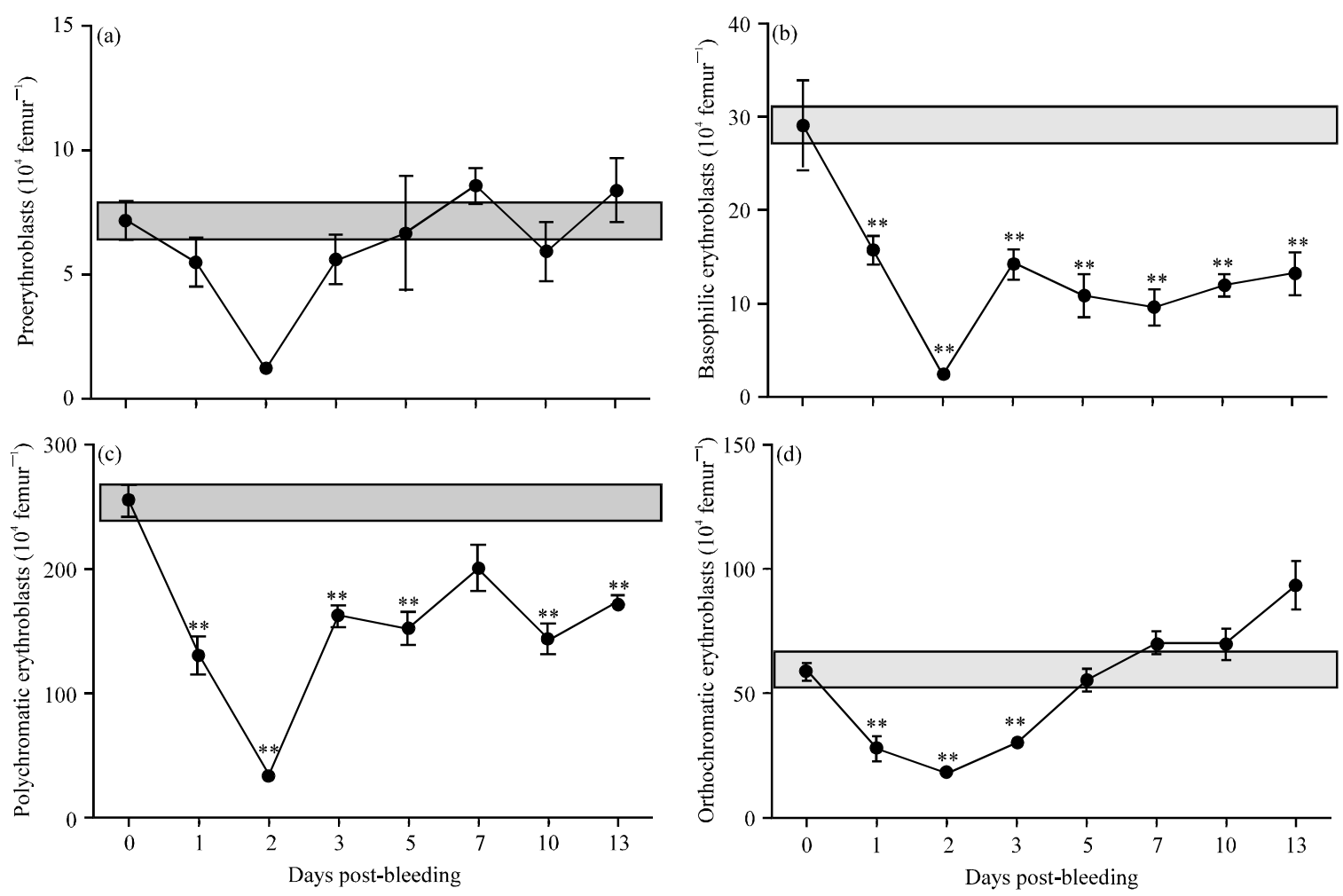

Fig. 2(a-d): Changes in erythroid bone marrow precursors after bleeding (a) Proerythroblasts ( $10^{4} /$ femur) (b) Basophilic erythroblasts $\left(10^{4} / \mathrm{femur}\right)$ (c) Polychromatophilic erythroblasts (10/femur) and (d) Ortochromatic normoblasts $\left(10^{4} /\right.$ femur), Data were obtained from three different assays. Results are represented as Mean $\pm \mathrm{SEM},{ }^{*} \mathrm{p}<0.05$ and ${ }^{* *} \mathrm{p}<0.01$, ANOVA and post hoc Dunnett test, between control group (day 0 ) and bled treated groups

BFU-E) on day 3 was coincident with the restoration of early erythroid precursors (proerythroblasts), in response to anaemia induced by bleeding.

Epo-receptor expression: The Epo-R was quantified by Western blotting analysis to observe changes in its expression in bone marrow cells during anaemic response (Fig. 5). Epo-R was over-expressed from 3-10 days, reaching maximal levels on the seventh day post bleeding (almost two times over the control, $\mathrm{p}<0.01$ ). Epo-R over expression on the third day was coincident with the increment of proerythroblasts counts and the enhancement of the CFU-E progenitors $(\mathrm{r}=0.89$; $\mathrm{p}=0.001$ ), as a direct target during erythroid stress recovery.

Bcl- $\mathbf{x}_{\mathrm{L}}$ and Bax expressions: To understand the mechanisms of apoptosis in bone marrow after bleeding, proteins of $\mathrm{Bcl}-2$ family were assessed: The pro-apoptotic $\mathrm{Bax}$ and the anti-apoptotic BCL-xL.
Bcl- $\mathrm{x}_{\mathrm{L}}$ immunodetection decreased between 1 and 2 days (1.3-0.7 fold below the control, $\mathrm{p}<0.05$ respectively) and it was over expressed from 5-15 days $(\mathrm{p}<0.01)$ (Fig. 6 a). Bax expression enhanced between 1 and 2 days ( 1.5 and 1.2 fold above control, $\mathrm{p}<0.01$, respectively) and decreased from the third day until the end of the experience (Fig. 6b). A direct correlation between apoptotic indexes vs. Bax expression was significantly noticed $(r=0.88 ; p=0.001)$. In this study, bleeding induced a significant increase in the pro-apoptotic Bax protein and a decrease of the levels of the anti-apoptotic $\mathrm{Bcl}-\mathrm{X}_{\mathrm{L}}$ protein, thus shifting the $\mathrm{Bax} / \mathrm{Bcl}-\mathrm{X}_{\mathrm{L}}$ ratio in favour of apoptosis.

Cytochrome c and Smac/DIABLO expression: To elucidate whether mitochondrial apoptotic pathway occur in bone marrow after acute blood-loss, cytochrome c and Smac/DIABLO expressions were assessed by immunoblottings. A significant increase in the amount of cytochrome c (Fig. 7) and Smac/DIABLO (Fig. 8) were observed from 1-3 days ( 2 fold over control, $\mathrm{p}<0.01$, 

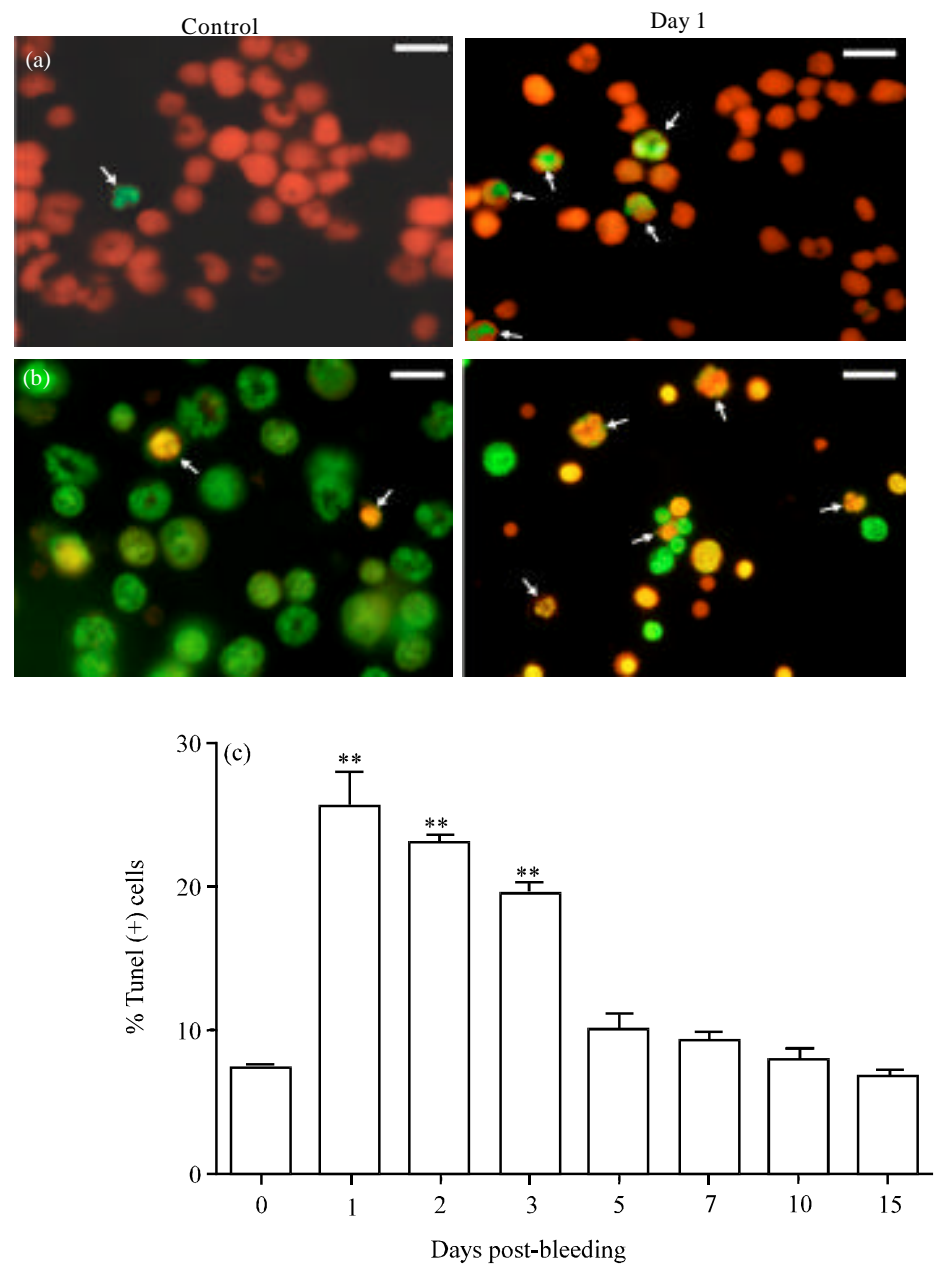

Fig. 3(a-c): Apoptosis in bone marrow cells post bleeding, Apoptotic biochemical and morphological changes were assessed by (a) Fluorescence assays with Acridine Orange (AO) and Ethidium Bromide (EB). Viable cells exhibit homogeneous green fluorescence. Apoptotic cells show nuclei with irregular bright red fluorescence as a result of chromatin condensation and nuclear fragmentation. Necrotic cells denote uniform red bright fluorescence. (b) TUNEL assay was used as a confirmatory technique to assess bone marrow apoptosis. Nuclei of apoptotic cells were stained positive for green fluorescence, Representative images (400 x) from the control group (day 0 ) and day 1 post bleeding are shown. Scale bars represent $30 \mu \mathrm{m}$ length. Arrows indicate apoptotic cells in each panel (c) Percentages of TUNEL positive cells related to total cells are represented. Five hundred cells were counted for each sample taken on the scheduled days, Results are expressed as Mean \pm SEM. ${ }^{* *} \mathrm{p}<0.01$ and ${ }^{* * *} \mathrm{p}<0.001$, ANOVA and post hoc Dunnett test, between control group (day 0 ) and bled treated groups

respectively). These results suggest that bleeding induced the mitochondrial dysfunction leading to cytochrome $\mathrm{c}$ and Smac/DIABLO release to cytosol and contribute to the apoptotic process, concomitant with Bax over-expression/Bcl- $\mathrm{x}_{\mathrm{L}}$ decrease.

Caspase-3 expression and enzymatic activity assay: Caspases, a family of cysteine proteases, are critical for programmed cell death (Fadeel et al., 2000). To determine the involvement of the active form of caspases- 3 in bone marrow post-bleeding, cleaved caspases- 3 immunoblottings and the enzymatic activity assay were performed.

These experiments indicate that the cleaved caspase-3 $(17 \mathrm{kDa})$ was significantly overexpresed from the first to the second day $(p<0.01)$, coincident with the 


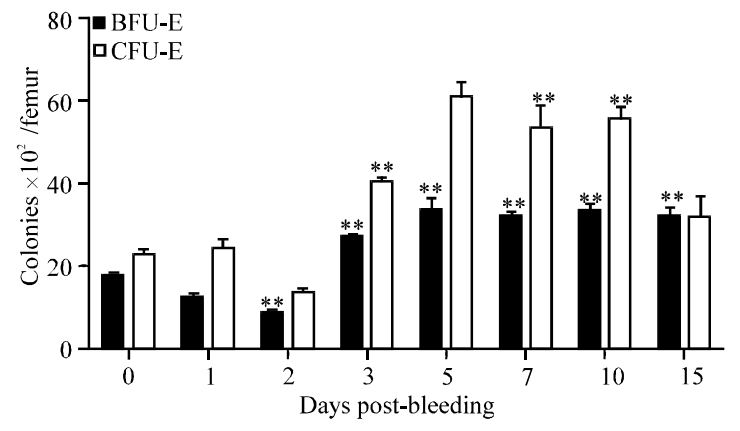

Fig. 4: Erythroid bone marrow progenitors after bleeding, BFU-E colonies were counted on day 7 of incubation and CFU-E colonies were scored on the second day of culture. Data were represented as the number of colonies $10^{2} /$ femur $(\mathrm{Mean} \pm \mathrm{SEM})$ from three different assays in triplicate, ${ }^{* *} \mathrm{p}<0.01$, ANOVA and post hoc Dunnett test, between control group (day 0 ) and bled treated groups

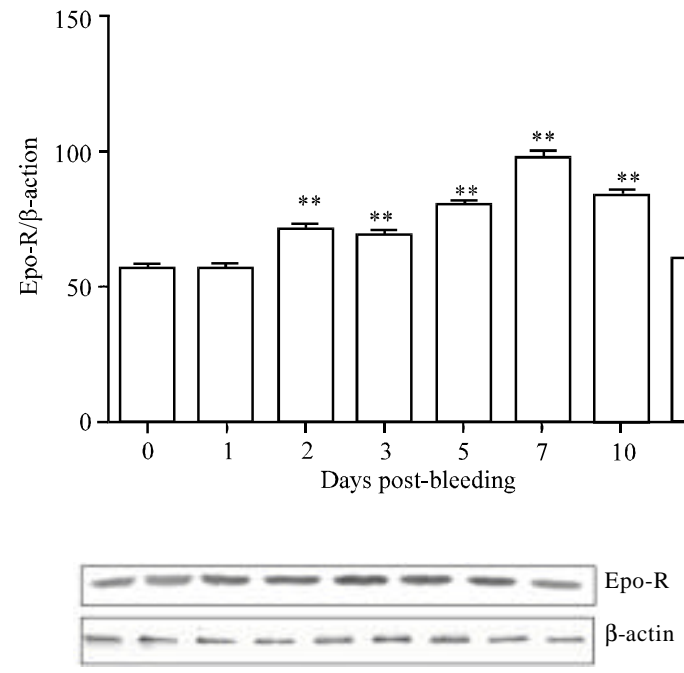

Fig. 5: Westernblotting of Epo-R in bone marrow post bleeding, A representative blot of three independent experiments is shown. Results represent the mean ratio: Epo-R $/ \beta$ actin \pm SEM of three mice per group, The $\beta$ actin was used as an internal control. Statistical significance: $\mathrm{p}^{* *}<0.01$ ANOVA and post hoc Dunnett test, compared to the control group (day 0 )

maximal apoptotic period. A direct correlation between apoptosis vs. cleaved caspase-3 expression was significantly $(r=0.91 ; p=0.001)$. Conversely, an expected overexpression the level of caspase- 3 was observed at 10 days $(\mathrm{p}<0.01$ ) (Fig. 9a). Changes in caspase- 3 activity in bone marrow lysates were assayed by a colorimetric
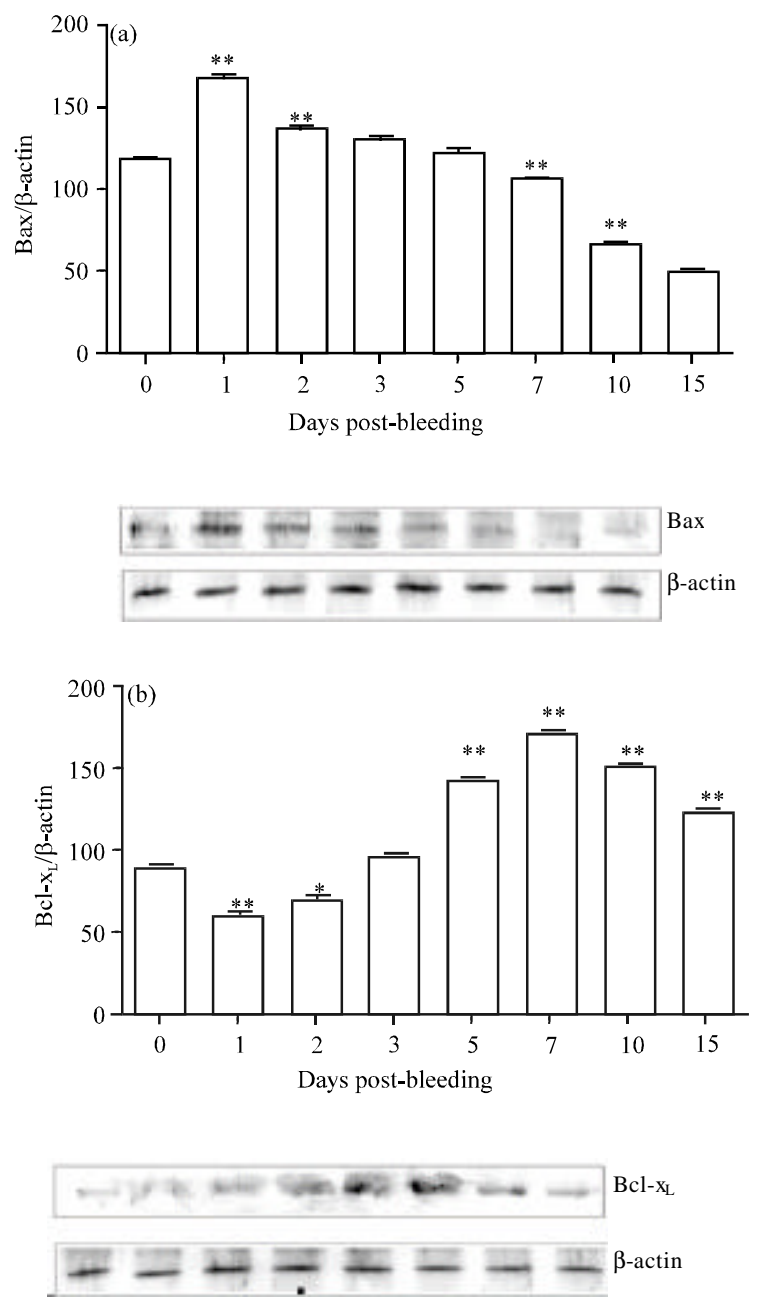

Fig. 6(a-b): Westernblotting of Bcl-xL and Bax in bone marrow post bleeding, Representative blots of three independent experiments are shown. The $\beta$-actin was used as an internal control. Statistical significance: ${ }^{*} \mathrm{p}<0.05$ and ${ }^{* *} \mathrm{p}<0.01$, ANOVA and post hoc Dunnett test, compared to the control group (day 0) (a) Bax expression. Bars represent the mean ratio: $\mathrm{Bax} / \beta$-actin $\pm \mathrm{SEM}$ of three mice per group and (b) Bcl- $\mathrm{x}_{\mathrm{L}}$ expression. Bars represent the mean ratio: $\mathrm{Bcl}-\mathrm{x}_{\mathrm{L}} / \beta$-actin $\pm \mathrm{SEM}$ of three mice per group

method (Ac-DEVD-pNA). Figure 9b, shows a 2 fold increase in caspase- 3 activity between the first and the second days $(p<0.01)$ compared to untreated cells.

These results agree with the increased of the cleaved caspase- 3 and the apoptotic process. From this reason, activated caspase-caspase-3 was involved in the apoptotic period (1-3 days) post-bleeding in coincident 

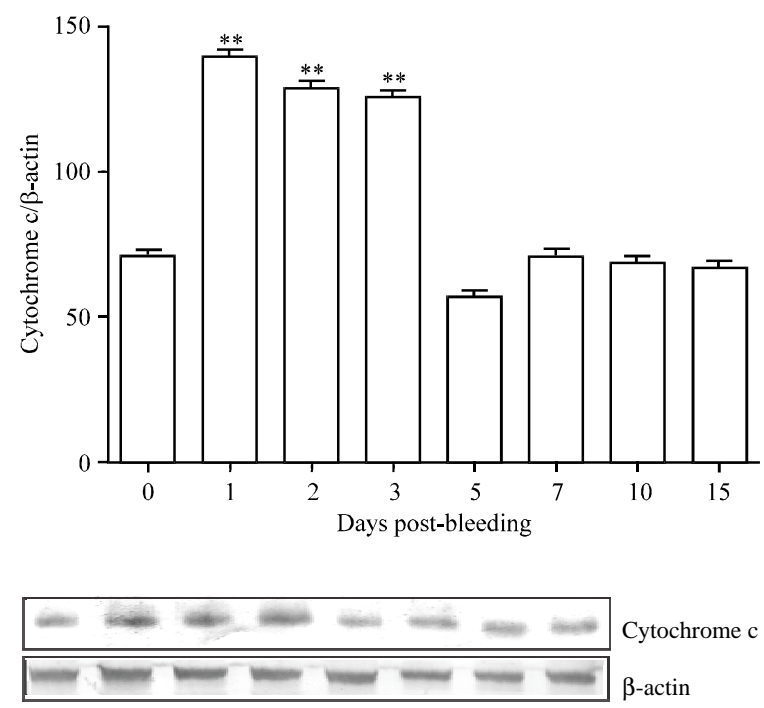

Fig. 7: Westernblotting of Cytochrome $\mathrm{c}$ in bone marrow post bleeding, Cytochrome $\mathrm{c}$ was overexpressed from day 1 to day 3 of the experience. The $\beta$-actin was used as an internal control. A representative blot of three independent experiments is shown. Results represent the mean ratio: Cytochrome $\mathrm{c} / \beta$ actin \pm SEM of three mice per group. Statistical significance: ${ }^{* *} \mathrm{p}<0.01$, ANOVA and post hoc Dunnett test, compared to the control group (day 0 )

with cytochrome $\mathrm{c}$ and Smac/DIABLO release from mitochondria to cytosolic compartment, concomitant with the higher expression of Bax.

Moreover, caspase-3 activity was increased $\sim 2$-fold at 10 days $(\mathrm{p}<0.01)$, in line with the cleaved caspase- 3 up regulation. This second caspase- 3 peak could be due to a post hypoxic response, when an excess of progenitors undergo apoptosis and the erythroid recovery is almost complete.

\section{DISCUSSION}

Basal and stress erythropoiesis occur in several cell stages developmental and are controlled by a complex molecular networks, acting in concert to meet the cell expansion in the erythropoietic compartment (Socolovsky, 2007). Most investigations about blood physiology in post-phlebotomy models were often confined to spleen cells (Sadahira et al., 2000) although they do not offer much information about bone marrow events linked to erythroid recovery.

To know more about the mechanism of anaemia after bleeding, we investigate in erythroid bone marrow cells
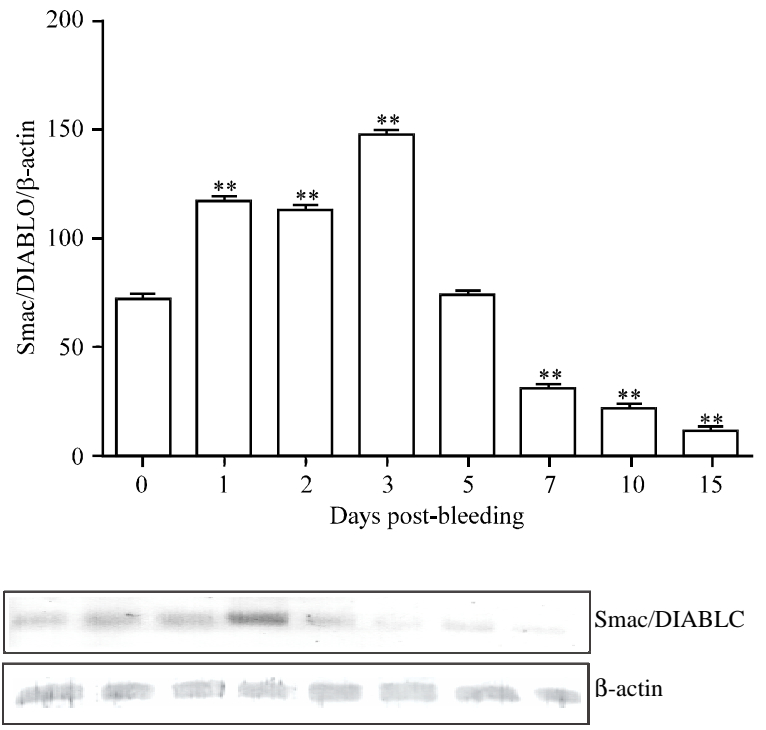

Fig. 8: Westernblotting of Smac/DIABLO in bone marrow post bleeding, The $\beta$ actin was used as an internal control. A representative blot of three independent experiments is shown. Results represent the mean ratio: $\mathrm{Smac} / \mathrm{DIABLO} / \beta$ actin \pm SEM of three mice per group. Statistical significance: ${ }^{* *} \mathrm{p}<0.01$, ANOVA and post hoc Dunnett test, compared to the control group (day 0 )

the intrinsic events, associated to apoptosis, growth and survival, evaluating the relative concentration of some Bcl-2 members, avoiding factors associated specifically with splenic stress erythropoiesis (Lenox et al., 2005).

The immediate effects after anaemic induction were a significant decrease in haematocrits and haemoglobin levels, whereas the reticulocyte production exhibited a compensatory response to blood-loss determining the magnitude of erythropoietic response to stress.

On day 3 , an increase of proerythroblasts was more remarkable in response to anaemic induction, while the number of polychromatic and orthochromatic normoblasts did not reached control values, probably by the accelerated input of the mature erythroid compartment released from bone marrow to blood stream upon stress. This prompt increment of the early erythroid precursors was driven in part by the enhancement of serum Epo.

An adequate haematopoietic response to anaemia induced by bleeding in mice is dependent on serum Epo level increment (Fisher, 2003). It has been reported that, Epo circulating levels increases from 1 to 3 days, reaching more than 20-fold basal values in anemic mice (Koury et al., 1989; Sadahira et al., 2000). As a consequence, bone marrow erythroid progenitors and 

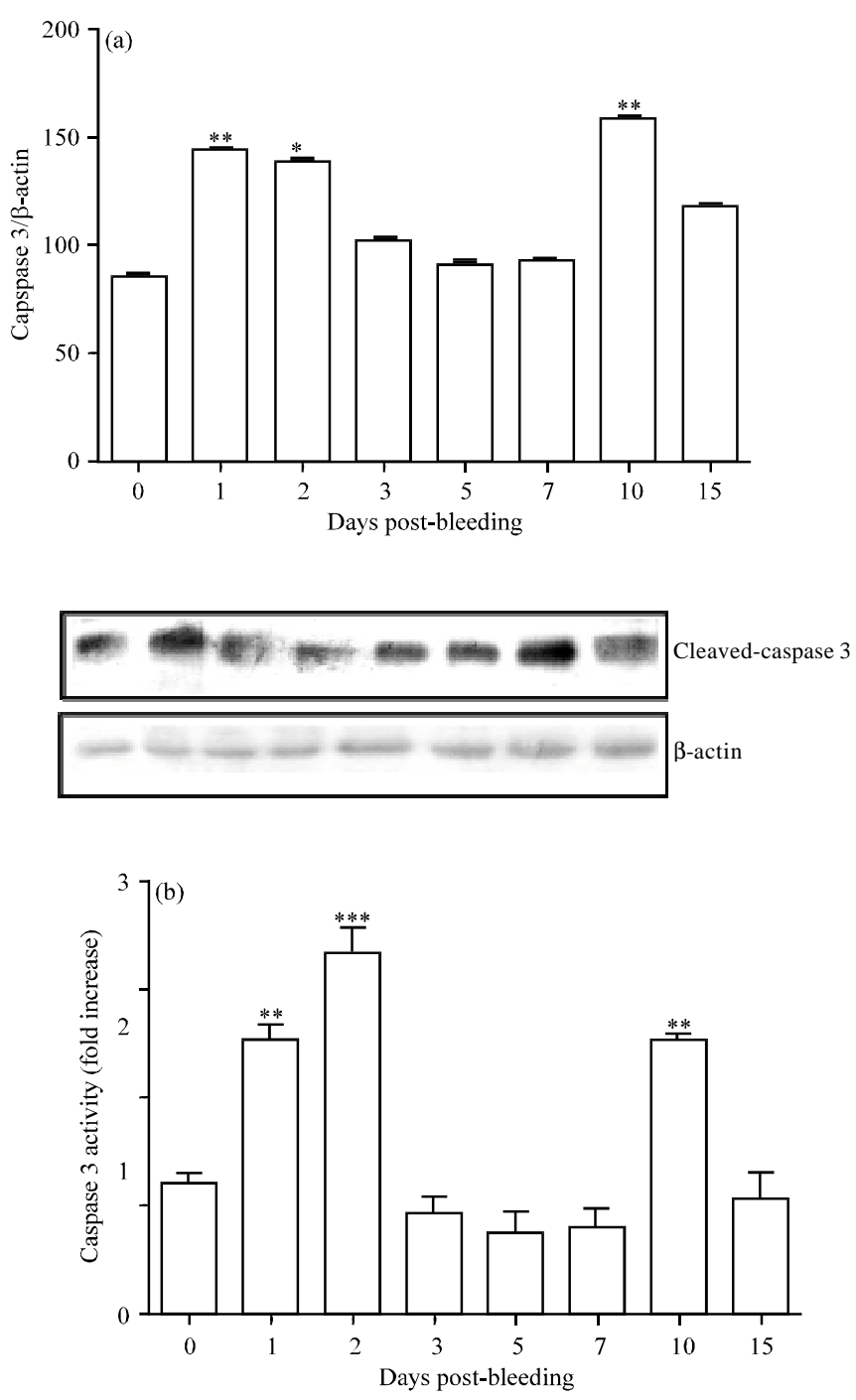

Fig. 9(a-b): Caspase-3 expression and enzyme activity in bone marrow post bleeding (a) Cleaved caspase-3 expression. Representative blots of three independent experiments are shown. Statistical significance: ${ }^{*} \mathrm{p}<0.05$ and ${ }^{* *} \mathrm{p}<0.01$, ANOVA and post hoc Dunnett test, compared to the control group (day 0) and (b) Caspase-3 activity assay, Caspase-3 activity was measured with a colorimetric assay kit that relies on caspase-mediated cleavage of p-nitroanilide (pNA) from a synthetic caspase substrate peptide (DEVD), data points represent mean fold induction $\pm \mathrm{SEM},{ }^{* *} \mathrm{p}<0.01$ and ${ }^{* * *} \mathrm{p}<0.001$ ANOVA and post hoc Dunnett test, compared to the control group (day 0 )

early erythroid precursors express higher levels of Epo-R making these cells more susceptible to the Epo influence (Testa, 2004).

Cellular changes assessed within of bone marrow erythroid compartment; suggest that the erythroid progenitors exhibit different proliferative and differentiation potentials.

On the second day post bleeding the number BFU-E immature progenitors decreased $(\mathrm{p}<0.01)$ while the frequency of CFU-E progenitors remained without significant changes. This fact could be due to the inhibitory effects of pro inflammatory mediators being released after bleeding on Epo production (Jelkmann, 2004), or by the physiological lag in the erythropoietic response to the endogenous Epo levels induced by tisular hypoxia. Both erythropoietic progenitors, BFU-E and CFU-E, expanded dramatically from the third day onwards. 


\section{J. Biol. Sci., 2013}

Therefore, the present experimental data are in agreement with previous reports indicating that BFU-E/CFU-E progenitors enhanced selectively to generate an adequate erythropoietic response after erythropoietic stress (Socolovsky et al., 2001; Liu et al., 2006).

In the present study, Epo-R expression was over expressed from 3 to 10 days. Results suggest that Epo-R potentially acts during multiple stages of erythroid differentiation and that the erythropoietic rate depends on the erythroid progenitors subsets rescued from apoptosis by Epo/Epo-R interaction. This profile is similar to the erythroid expansion communicated using another experimental anaemic settings (Wickrema et al., 1991; Aispuru et al., 2008).

The action of Epo levels, through its receptor (Epo-R) appears to activate a graded of antiapoptotic signals rescuing large number of early erythroblasts from apoptosis. This effect has been shown to be mediated by the expression of Bcl- $\mathrm{x}_{\mathrm{L}}$, an antiapoptotic protein of Bcl-2 family required for erythroid cell survival (Dolznig et al., 2002).

On the other hand, $\mathrm{Bcl}-\mathrm{x}_{\mathrm{L}}$ not only compensates the Epo-R loss by bleeding but can also significantly expand the available population of BFU-E and its output to mature erythrocytes. Thus, in this regard, erythroid bone marrow cells could be recovered in a much more rapid sequence.

The up-regulation of Bax levels with a concomitant down-regulation of $\mathrm{Bcl}-\mathrm{x}_{\mathrm{L}}$ between 1 and 2 days, suggests that the changes in the $\mathrm{Bax} / \mathrm{Bcl}-\mathrm{x}_{\mathrm{L}}$ ratio, could allow Bax to be available to signal apoptosis leading to a higher erythroid cell death.

The present study demonstrated that bleeding leads to the injury of the mitochondrial membrane, with the subsequent release of cytochrome $\mathrm{c}$ and Smac/DIABLO to the cytosolic compartment, associated with the activation of caspase- 3 playing the central role in the initiation of apoptosis from 1 to 3 days. Moreover, TUNEL and double stained fluorescent assays revealed a remarkable increment of apoptotic indexes on day 2 , indicating an acute apoptotic period.

Bcl- $\mathrm{x}_{\mathrm{L}}$ is overexpressed during the recovery period (5-10 days), which in turn prevents cytochrome $c$ and Smac/DIABLO translocations to cytosol in agreement with previous study (Sun et al., 2002). Thereafter, Bcl- $\mathrm{x}_{\mathrm{L}}$ plays a crucial role in the maintenance of the renewal and survival capacity of erythroid progenitor cells during erythropoietic restoration.

The contribution of the extrinsic FasR (CD95) and caspases- 3 activation on cell death pathway as well as
Epo-R expression has been described in a haemorrhagic shock model on murine bone marrow in a short time period (Robinson et al., 2008). The present experimental data, obtained from a longer course time study, contribute to new knowledge about the intrinsic apoptotic pathway in bone marrow cells after bleeding. It seems that there is an in vivo cross-talk between these two pathways that collectively amplify apoptotic events involving mitochondria, leading to activation of caspase- 3 , as the central executioner of cell death.

\section{CONCLUSION}

We demonstrate that the erythropoiesis after bleeding is dependent on a delicate balance among pro-apoptotic molecules such as Bax, caspase-3cytochrome c, Smac/DIABLO and pro-survival Epo-R and $\mathrm{Bcl}-\mathrm{x}_{\mathrm{L}}$ proteins, which are the crucial regulators in bone marrow erythroid cells recovery.

These findings provide new insights into the complex homeostatic mechanisms which promote erythropoietic response post-bleeding and might be useful for therapeutic interventions.

\section{ACKNOWLEDGMENTS}

This study was supported by grants from CONICET (PIP 01320) and SGCyT-UNNE (PI 17//060 andPI 17/I061). Stoyanoff T.R. is a recipient of a graduate fellowship of CONICET/UNNE.

\section{REFERENCES}

Adrain, C. and S.J. Martin, 2001. The mitochondrial apoptosome: A killer unleashed by the cytochrome seas. Trends Biol. Sci., 26: 390-397.

Aguirre, M., J. Juaristi, M. Alvarez and N. Brandan, 2005. Characteristics of in vivo murine erythropoietic response to sodium orthovanadate. Chem. Biol. Interact., 156: 55-68.

Aguirre, M.V., J.S. Todaro, J.A. Juaristi and N.C. Brandan, 2010. Murine erythropoietic impairment induced by Paclitaxel: Interactions of GATA-1 and erythroid Kruppel-like transcription factors, apoptotic related proteins and erythropoietin receptor. Eur. J. Pharmacol., 636: 42-51.

Aispuru, G.R., M.V. Aguirre, J.A. Aquino-Esperanza, C.N. Lettieri, J.A. Juaristi and N.C. Brandan, 2008. Erythroid expansion and survival in response to acute anemia stress: The role of EPO receptor, GATA-1, Bcl-xL and caspase-3. Cell Biol. Int., 32: 966-978. 
Broudy, V.C., N. Lin, M. Brice, B. Nakamoto and T. Papayannopoulou, 1991. Erythropoietin receptor characteristics on primary human erythroid cells. Blood, 77: 2583-2590.

Cory, S. and J.M. Adams, 2002. The Bcl2 family: Regulators of the cellular life-or-death switch. Nat. Rev. Cancer, 2: 647-656.

Deng, Y., Y. Lin and X. Wu, 2002. TRAIL-induced apoptosis requires Bax-dependent mitochondrial release of Smac/DIABLO. Genes Dev., 16: 33-45.

Dolznig, H., B. Habermann, K. Stangl, E.M. Deiner and R. Moriggl et al., 2002. Apoptosis protection by the Epo target Bcl-XL allows factor-independent differentiation of primary erythroblasts. Curr. Biol., 12: 1076-1085.

Erslev, A.J. and E. Beutler, 1995. Production and Destruction of Erythrocytes. In: Williams Hematology, Beutler, E., M.A. Lichtman, B.S. Coller and I.J. Kipps (Eds.). McGraw-Hill Inc, New York, pp: 425-441.

Fadeel, B., S. Orrenius and B. Zhivotovsky, 2000. The most unkindest cut of all: On the multiple roles of mammalian caspases. Leukemia, 14: 1514-1525.

Fisher, J.W., 2003. Erythropoietin: Physiology and pharmacology update. Exp. Biol. Med., 228: 1-14.

Gregoli, P.A. and M.C. Boundurant, 1997. The roles of $\mathrm{Bcl}-\mathrm{X}$ (L) and apopain in the control of erythropoies is by erythropoietin. Blood, 90: 630-640.

Gregory, T., C. Yu, A. Ma, S.H. Orkin, G.A. Blobel and M.J. Weiss, 1999. GATA-1 and erythropoietin cooperate to promote erythroid cell survival by regulating bcl-xL expression. Blood, 94: 87-96.

Hara, H. and M. Ogawa, 1977. Erythropoietic precursors in mice under erythropoietic stimulation and suppression. Exp. Hematol., 5: 141-148.

Jelkmann, W., 2004. Molecular biology of erythropoietin. Int. Med., 43: 649-659.

Koury, S.T., M.J. Koury, M.C. Bondurant, J. Caro and S.E. Graber, 1989. Quantitation of erythropoietinproducing cells in kidneys of mice by in situ hybridization: Correlation with hematocrit, renal erythropoietin mRNA and serum erythropoietin concentration. Blood, 74: 645-651.

Launay, S., O. Hermine, M. Fontenay, G. Kroemer, E. Solary and C. Garrido, 2005. Vital functions for lethal caspases. Oncogene., 24: 5137-5148.

Lenox, L.E., J.M. Perry and R.F. Paulson, 2005. BMP4 and Madh5 regulate the erythroid response to acute anemia. Blood, 105: 2741-2748.

Liu, Y., R. Pop, C. Sadegh, C. Brugnara and V.H. Haase et al., 2006. Suppression of Fas-FasL coexpression by erythropoietin mediates erythroblast expansion during the erythropoietic stress response in vivo. Blood, 108: 123-133.
Parsons, M.J. and D.R. Green, 2010. Mitochondria in cell death. Essays Biochem., 47: 99-114.

Rhodes, M.M., P. Kopsombut, M.C. Bondurant, J.O. Price and M.J. Koury, 2005. Bcl-X (L) prevents apoptosis of late-stage erythroblasts but does not mediate the antiapoptotic effect of erythropoietin. Blood, 106: 1857-1863.

Robinson, Y., A. Matenov, S.K. Tschoke, A. Weimann and A. Oberholzer et al., 2008. Impaired erythropoiesis after haemorragic shock in mice is associated with erythroid progenitor apoptosis in vivo. Acta. Anaesthesiol. Scand, 52: 605-613.

Romero Benitez, M.M.I., M.V. Aguirre, J.A. Juaristi, M.A. Alvarez and J.M. Trifaro et al., 2004. In vivo erythroid recovery following Paclitaxel injury: correlation between GATA-1, c-MYB, NF-E2, EPO receptor expressions and apoptosis. Toxicol. Appl. Pharmacol., 194: 230-238.

Sadahira, Y., T. Yasuda, T. Yoshino, T. Manabe and T. Takeishi et al., 2000. Impaired splenic erythropoiesis in phlebotomized mice injected with CL2MDP-liposome: An experimental model for studying the role of stromal macrophages in erythropoiesis. J. Leuk. Biol., 68: 464-470.

Silva, M., A. Benito, C. Sanz, F. Prosper and E. Daryoush et al., 1999. Erythropoietin can induce the expression of Bcl-xL through stat 5 in erythropoietin-dependent progenitor cell lines. J. Biol. Chem., 274: 22165-22169.

Socolovsky, M., 2007. Molecular insights into stress erythropoiesis. Curr. Opin. Hematol., 14: 215-224.

Socolovsky, M., H. Nam, M.D. Fleming, V.H. Haase and C. Brugnara et al., 2001. Ineffective erythropoies is in Stat5a (__) 5b (_ _ mice due to decreased survival of early erythroblasts. Blood, 98: 3261-3273.

Sun, X.M., S.B. Bratton, M. Butterworth, M. MacFarlane and G.M. Cohen, 2002. Bcl-2 and Bcl-xL inhibit CD95-mediated apoptosis by preventing mitochondrial release of Smac/DIABLO and subsequent inactivation of X-linked inhibitor-ofapoptosis protein. J. Biol. Chem., 277: 11345-11351.

Testa, U., 2004. Apoptotic mechanisms in the control of erythropoiesis. Leukemia., 18: 1176-1199.

Wallach, D., T.B. Kang and A. Kovalenko, 2008. The extrinsic cell death pathway and the elan morte. Cell. Death. Differ., 15: 1533-1541.

Wickrema, A., M.C. Bondurant and S.B. Krantz, 1991. Abundance and stability of erythropoietin receptor mRNA in mouse erythroid progenitor cells. Blood, 1: 2269-2275. 